\title{
SPATIAL AND TEMPORAL ECOLOGY OF OAK TOADS (BUFO QUERCICUS) ON A FLORIDA LANDSCAPE
}

\author{
Cathryn H. Greenberg ${ }^{1,3}$ and George W. Tanner ${ }^{2}$ \\ ${ }^{1}$ USDA Forest Service, Southern Research Station, Bent Creek Experimental Forest, \\ 1577 Brevard Rd., Asheville, NC 28806, USA \\ ${ }^{2}$ Department of Wildlife Ecology and Conservation, Institute of Food and Agricultural Sciences, \\ Newins Zeigler 303, Box 110430, University of Florida, Gainesville, FL 32611-0430, USA
}

\begin{abstract}
We used data from 10 years of continuous, concurrent monitoring of oak toads at eight isolated, ephemeral ponds in Florida longleaf pine-wiregrass uplands to address: (1) did weather variables affect movement patterns of oak toads?; (2) did pond hydrology and the condition of surrounding uplands affect pond selection by adults or juvenile recruitment?; (3) were population trends evident?; and (4) did a classical metapopulation model best represent their population ecology? Of 4076 oak toads captured, 92.2\% were adults. Substantial ( $n \geq 30$ exiting juveniles) recruitment occurred only three times (once each at three ponds during two years). Males outnumbered females (average for all years 2.3:1). Most captures occurred during May-September. Adult captures during June-August increased with heavier rainfall but were not influenced by the durations of preceding dry periods. Movement patterns of metamorphs suggested that oak toads emigrated when moisture conditions become favorable. Pond use by adults was correlated with maximum change in pond depth (May-September). Juvenile recruitment was negatively correlated with minimum pond depth and the number of weeks since a pond was last dry, and positively correlated with the maximum number of weeks a pond held water continuously. The number of breeding adults and juvenile recruitment were highest at ponds within the hardwood-invaded upland matrix. The direction of most immigrations and emigrations was nonrandom, but movement occurred from all directions, and the mean direction of pond entry and exit did not always correspond. A total of $21.1 \%$ of individuals was recaptured; $13.3 \%$ of first captures were recaptured during the same year, and $7.7 \%$ during a subsequent year. Only $1.9 \%$ of captured oak toads moved among ponds, mostly within a distance of $132 \mathrm{~m}$. We did not detect adult population trends over the 10 yr studied. Presence or absence at ponds in any given year was a poor indicator of overall use. We saw little evidence of local extinction or "rescue," but were unable to determine whether juveniles returned to natal ponds or colonized new ponds for breeding as adults. Oak toad conservation can best be ensured by maintaining multiple ponds within a landscape to increase the probability of recruitment within the landscape neighborhood during at least some years and at some ponds, and to increase the likelihood of interpond movement.
\end{abstract}

Key words: Amphibian populations; Anuran breeding; Bufo quercicus; Ephemeral ponds; Hydroperiod; Metapopulation; Oak toads; Temporary wetlands; Wetlands

A DEARTH of long-term studies of amphibian populations restricts our understanding of population dynamics and our ability to distinguish true population trends from natural fluctuations (Blaustein, 1994). The few longterm studies typically have been conducted at a single site (Dodd, 1992; Semlitsch et al., 1996). Such studies provide important information about life history and patterns of pond use, but cannot provide the larger, landscapelevel perspective that is gained by sampling multiple ponds within a landscape. The logistical and fiscal constraints that prevent intensive sampling at multiple ponds often lead to "snapshot" sampling to assess amphibian distribution or richness by presence/absence

\footnotetext{
${ }^{3}$ Correspondence: e-mail, kgreenberg@fs.fed.us
}

surveys (Skelly et al., 1999; Skelly et al., 2003). Such surveys are likely to miss species presence and certainly miss information on population and metapopulation dynamics.

Metapopulation theory, which holds that subpopulations become locally extinct and are recolonized by migrations from other subpopulations (Hanski and Simberloff, 1997), is a popular paradigm and is increasingly applied to amphibian ecology. Most studies use presence/absence surveys at ponds to determine the occurrence of populations. Presence of a species followed by absence (no detection) the following year indicates extinction, whereas absence followed by presence during the next year indicates recolonization (see review in Marsh and Trenham, 2001). This "ponds as patches" (Marsh and Trenham, 2001) approach assumes, in part, that (1) surveys at 
ponds detect the presence or absence of a species; (2) absence is in fact an indicator of local extinction; and (3) recolonization, or inter-pond movement, is a common occurrence but decreases with increasing distances among ponds. However, each of these assumptions is questionable. Many amphibian species skip breeding during some years but are nonetheless present (i.e., not extinct) in the surrounding uplands (Semlitsch, 1996). Many amphibians also visit ponds mainly during short, explosive breeding periods, increasing the likelihood that they will be considered "absent" (Greenberg and Tanner, 2004). Finally, many pond-breeding amphibian species are highly philopatric, thus reducing the likelihood of inter-pond movement (Blaustein et al., 1994). The temporal and spatial variability in breeding, recruitment, population structure, and metapopulation organization-or lack thereof-can be captured only with intensive, concurrent, and continuous mark-recapture sampling of multiple ponds within a landscape over an extended period.

Like many amphibian species in the southeastern United States, oak toads (Bufo quercicus) breed primarily in isolated, temporary, fish-free ponds (Moler and Franz, 1987) but inhabit the surrounding uplands during most of their adult lives. Hamilton (1955) described them as "extraordinarily abundant." Carr (1940) wrote that ... "Today I believe it would be possible to cross central Florida by car and at no time be in a situation where the calls of quercicus were not audible." Documentation of their basic natural history has been limited primarily to observation (Carr, 1940; Hamilton, 1955; Wright, 2002) or studies at a single site (Dodd, 1994). Because there have been no studies of oak toads at a broad spatial and temporal scale, little is known of how the condition of surrounding uplands affects pond use, how weather affects activity and breeding, what factors influence the selection of breeding ponds by adults, or the likelihood of successful recruitment. To our knowledge, no studies have addressed the spatial and temporal dynamics of breeding ecology and recruitment, or whether a metapopulation model best describes the population ecology of oak toads.

We used data from 10 years of continuous, concurrent monitoring at eight isolated, ephemeral ponds in Florida longleaf pine (Pinus palustris)-wiregrass (Aristida beyrichiana) uplands to examine spatial and temporal ecology of oak toads. Half of the ponds were in sandhills that had been invaded by hardwoods and sand pine (Pinus clausa) as a consequence of fire suppression, and half were in regularly burned, savanna-like sandhills. We asked (1) did weather variables affect movement patterns of oak toads?; (2) did pond hydrology and the condition of surrounding uplands affect pond selection by adults, or juvenile recruitment?; (3) were population trends detected?; and (4) did a classical metapopulation model best represent the spatial and temporal dynamics of oak toad breeding, recruitment, and movement?

\section{Methods}

Our study ponds were eight small (0.1-0.37 ha), isolated, ephemeral sinkhole ponds in longleaf pine-wiregrass sandhills on the Ocala National Forest, Marion and Putnam Counties, Florida. Ponds 1-4 were in sandhills that had been invaded by hardwoods and sand pine as a result of fire suppression. Despite attempts at habitat restoration (hardwood reduction) by burning at 1-4 year intervals during the past two decades, hardwood density and wiregrass cover remained patchy. Ponds 5-8 were in savanna-like sandhills with a continuous wiregrass ground cover, widely spaced longleaf pine trees, and few hardwoods. Since 1976 this upland matrix has been burned regularly at 2-3 year intervals (for more detailed habitat characteristics see Greenberg, 2001). Ponds 1-3 were closely spaced (all within $132 \mathrm{~m}$ of one another) within $10-30 \mathrm{~m}$ of the regularly burned sandhills on one side, separated by a sand road. Ponds $1-7$ were all within about $0.7 \mathrm{~km}$ of one another. Ponds 7 and 8 were approximately $9.5 \mathrm{~km}$ south of the others.

\section{Drift Fence Sampling}

We installed drift fences 7.6-m long and spaced 7.6-m apart around the perimeter of each pond near the high water line, such that $50 \%$ of each pond was fenced, with fences and spaces equally distributed around the entire pond. The distances between fences and pond edges varied with pond depths. We placed 
pitfall traps (19-l buckets) inside and outside of each end of each fence (four buckets per fence) to detect directional movement by amphibians to and from ponds. We placed a sponge in each pitfall trap, and moistened them as needed during trap checks to reduce the likelihood of desiccation. We positioned a double- or single-ended funnel trap at the midpoint of each fence on both sides (two per fence).

We checked the traps three times weekly from February 1994 through January 2004. We measured the snout-vent length (SVL), and mass to the nearest $0.1 \mathrm{~g}$ using a hand-held Pesola spring scale, of all juveniles and about half of all first-captured adults (some were not measured if capture rates were high). Adults were sexed and marked by pond number and year of capture by toe clipping. Males could be distinguished from females by having a darkcolored throat and dusky venter (Wright, 2002). Oak toad metamorphs could be distinguished from southern toad (B. terrestris) metamorphs by their more prominent light middorsal stripe, often orange toes, and head shape (southern toads have a more spatulate head and flatter nose). Newly metamorphosed toads were not marked, as they were too small to toe-clip (mean SVL of juveniles JuneOctober, all years, was $11.7 \mathrm{~mm}$ but many were $6-8 \mathrm{~mm}$ SVL). Animals were released on the opposite side of the fence from their capture point.

We measured water depths weekly beginning in March 1994, and recorded temperature and rainfall daily at $0700 \mathrm{~h}$ beginning in April 1994. Beginning in January 1997, we recorded minimum and maximum daily temperature, and barometric pressure and relative humidity were recorded using automatic loggers at 3-h intervals. We used a Geographic Positioning System (GPS) to estimate interpond distances.

\section{Statistical Analyses}

We used Wright's (2002) cohort classifications based on estimated growth rates to classify individuals as $<1-y r$ old "juveniles" ( $<20 \mathrm{~mm}$ ), or 1-yr-old (20-29 mm), or 2-yr-old (30-39 mm) "adults". Both the juvenile and 1-yr-old categories likely included some nonbreeding subadults. For statistical analyses we considered all individuals $\geq 20 \mathrm{~mm}$ as adults.
We used repeated measures 2-way Analysis of Variance (ANOVA) to test for differences in pond use between upland matrices and among years by all adults (entering and exiting), and by recruits (using only exiting neonates as a conservative estimate of recruitment). Data were standardized to number of captures per 100 trapnights for these analyses, because ponds of different sizes had different numbers of traps, and some traps were flooded (closed) during high water. Virtually all $(98.5 \%)$ movement by adult oak toads occurred during MaySeptember, and most (95.0\%) movement by juveniles occurred during June-October. We included only these months in our analyses of upland matrix treatment effects to reduce potential bias introduced by having more traps closed and different proportions of total traps closed among ponds during winter flooding, when oak toad captures were negligible.

We used stepwise multiple regression to explore the relationship between landscapelevel (ponds combined) movement (captures per 2-3 day trapcheck interval) of adults and juveniles (separately) and weather variables including: cumulative rainfall, number of prior 2-3-day trapcheck intervals with no $(<0.3 \mathrm{~cm})$ rainfall, temperature (mean minimum, minimum, mean maximum, maximum, and mean daily), barometric pressure (mean daily, minimum, maximum, and maximum change per 2-3 day trapcheck interval), relative humidity (mean daily, minimum, maximum, and maximum change per 2-3 day trapcheck interval), and an interaction term between cumulative precipitation and maximum change in barometric pressure per 2-3 day trapcheck interval. For adults we performed two stepwise regressions: one using both year-round data, to determine whether weather variables affected the commencement of activity in spring, and another using only June-August data (when $92.6 \%$ of captures occurred), to examine the relationship between weather variables and capture rates during their peak active season. For juveniles we limited our correlation dataset to months when they were most frequently captured (June-October) and years when recruitment was substantial $(n \geq 30)-1994$, 1998, and 2002.

To assess whether hydrology affected pond selection by breeding adults, we used stepwise multiple regression to correlate rainfall and 
hydrological characteristics of ponds during May-September, and the number of firstcaptured adults (May-September). Capture data were standardized to number per 100 trapnights and log-transformed. Independent variables (per pond for 10 years; $n=80$ ) were: number of weeks a pond was dry; number of weeks a pond was wet $(\geq 2 \mathrm{~cm})$; minimum, maximum, and maximum change in depth; number of times a pond refilled after drying; number of weeks since a pond was last dry $(0$ if it was dry during the first week of May when the data period began); maximum number of weeks a pond continuously held water; total precipitation; and an interaction between the maximum number of weeks a pond continuously held water and the number of weeks since a pond was last dry.

To assess whether pond hydrology and breeding effort affected recruitment rates, we used stepwise multiple regression to correlate the number of breeding adults, rainfall, and hydrological characteristics of ponds (using the variables described above) during May-September with oak toad recruitment (exiting juveniles, June-October). We used standardized (per 100 trapnights) capture data for adults and recruits.

We used a compass to obtain an azimuth from the center of each pond to every pitfall trap. Under the assumption that captures by intermittent, equally spaced drift fences permitted detection of directional movement in some (if not $50 \%$ ) proportion to its occurrence, we used the nonparametric Rayleigh test (Zar, 1984) to determine whether the annual emigration or immigration movements of adults or juveniles (if $n \geq 30$ ) were nonrandom.

We used paired $t$-tests to compare the proportion of first-captured males to females per pond, and a 1-way ANOVA to examine whether the proportion of males differed among years, using ponds as replicates. Oneway ANOVA also was used to assess whether the proportion of males to females differed among months, using years as replicates (ponds combined). Only months (for analyses using months), or years (for analyses using years) having $n \geq 10$ sexed adults were included in analyses. Student's $t$-tests were used to compare SVL and mass between male and female oak toads. We omitted 1994 data from these analyses because oak toads were not sexed that year. We examined adult population trends over the 10-year study period using Pearson's product-moment correlations between study year and number of firstcaptured adults. We used square-root or log-transformations on data to reduce heteroscedasticity. All proportions were arcsine square-root transformed for analyses.

\section{RESUlts}

\section{Population Structure}

We captured a total of 4076 oak toads during our 10-yr study. Most (92.2\%) were adults $(\geq 20 \mathrm{~mm})$; relatively few juveniles $(7.8 \%)$ were captured. Substantial recruitment ( $n \geq 30$ juveniles exiting a pond) was detected only 3 times (at Ponds 2 and 4 during 1994, and at Pond 3 in 1998). Males $(69.4 \% \pm 2.1 \%)$ were captured more frequently than females (average for all years $30.6 \% \pm 2.1 \%$ ) during all years $(t=-3.61$; df $=170 ; P<0.0001)$. However, the proportion of males was significantly higher in 2001 and 2002 than in most other years (there were fewer males in 1998 than in 1997, and 1997 did not differ from 2002) $\left(F_{8,33}=12.98 ; P<0.0001\right)$. The proportion of males to females was similar among tested months (June-September) $\left(F_{3,22}=0.66\right.$; $P=0.5855$ ). Adult males were smaller (mean $\mathrm{SVL} \pm \mathrm{SE} 28.7 \pm 0.1 \mathrm{~mm} ; t=15.81 ; \mathrm{df}=$ 1388; $P<0.0001$ ) and lighter (mean mass \pm SE $2.1 \pm 0.0 \mathrm{~g} ; t=17.70$; df $=1313 ; P<$ 0.0001 ) than females (mean SVL \pm SE $31.5 \pm$ $0.2 \mathrm{~mm}$; mean mass $\pm \mathrm{SE} 2.9 \pm 0.1$ ). Mean ( \pm SE) SVL and body mass of juveniles (defined as $<20 \mathrm{~mm}$ ) were $11.8 \pm 0.2 \mathrm{~mm}$ (range 6-19 $\mathrm{mm}$ ) and $0.25 \pm 02 \mathrm{~g}$, respectively.

\section{Influence of Weather on Movement}

Oak toad activity was highly seasonal. Nearly all (98.5\%) adult captures occurred during May-September; peak movement (92.6\%) was June-August (Figs. 1, 2). Most (95.0\%) movement by juveniles occurred during June-October. When year-round data were used, movement by adult oak toads was positively correlated with cumulative rainfall $(P<0.0001)$, maximum temperature $(P<$ 0.0001 ), and an interaction between cumulative rainfall per trapcheck interval and the number of prior trapcheck intervals having no rainfall $(P<0.0001)\left(F_{3,810}=99.66 ; P<0.0001\right.$; 


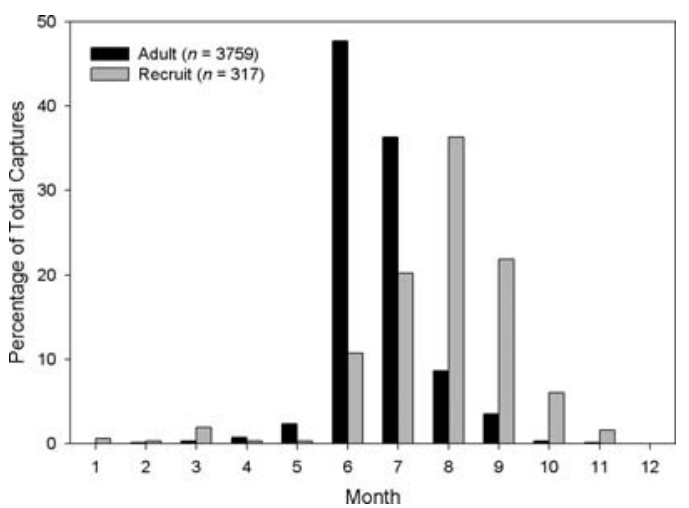

FIG. 1.-Monthly proportion (all years combined) of adult and juvenile oak toads captured during Feb. 1993Jan. 2004 at eight isolated, ephemeral ponds within longleaf pine-wiregrass sandhills, Ocala National Forest, Marion and Putnam Counties, Florida, U.S.A.

$r^{2}=0.27 ;$ RMSE $\left.=1.31\right)$. Movement of adults during their peak active season (June-August) was positively correlated with cumulative rainfall $(P<0.0001)$ and negatively correlated with maximum barometric pressure $(P=$ $0.0177),\left(F_{2,246}=108.82 ; P<0.0001 ; r^{2}=\right.$ 0.47 ; RMSE $=1.82$ ) (Fig. 3). Movement by juveniles (June-October) was positively correlated with maximum temperature $(P<$ $0.0001)$, mean daily barometric pressure $(P=0.0094)$, and an interaction between cumulative precipitation and the number of prior trapcheck intervals having no rain $(P<$ $0.0001)$, and was negatively correlated with maximum change in relative humidity $(P=$ $0.0396),\left(F_{4,124}=24.53 ; P<0.0001 ; r^{2}=\right.$ $0.44 ; \operatorname{RMSE}=0.51)$.

\section{Influence of Hydrology on Breeding and Recruitment}

Pond use by adult oak toads during MaySeptember was correlated only with maximum change in pond depth $(P<0.0013)\left(F_{1,77}=\right.$ 11.08; $P<0.0013 ; r^{2}=0.13$; RMSE $\left.=0.99\right)$. Oak toad recruitment was negatively correlated with minimum pond depth $(P=0.0005)$ and the number of weeks since a pond was last dry $(P=0.0024)$, and positively correlated with the maximum number of weeks a pond continuously held water $(P=0.0001)\left(F_{3,75}=\right.$ 11.84; $P<0.0001 ; r^{2}=0.27$; $\left.\operatorname{RMSE}=0.54\right)$.

\section{Upland Matrix Treatment Effects}

The number of breeding adults at ponds was higher within the hardwood-invaded upland matrix than in the savanna-like longleaf pinewiregrass matrix $(\mathrm{df}=1 ; F=8.26 ; P=$ 0.0058 ). There was a repeated measures effect $(F=4.44 ; \mathrm{df}=6 ; P=0.0010)$, but no effect of year, nor was a year $\times$ treatment interaction detected $(P \geq 0.23)$. Similarly, significantly more juveniles were produced from ponds within the hardwood-invaded upland matrix than from ponds in the savanna-like sandhills matrix $(F=25.31$; df $=1 ; P<0.0001)$. Recruitment also differed among years $(F=$ 6.63; $\mathrm{df}=9 ; P<0.0001)$. There were more recruits in 1994 than in other years, and the number of recruits in 2002 did not differ from those in other years. A year $\times$ treatment effect was detected $(F=6.72$; df $=9 ; P<$ 0.0001 ), but there was no repeated measures effect $(F=1.20$; $\mathrm{df}=6 ; P=0.3184)$.

\section{Orientation}

Many (27 of 40) of the adult immigration and emigration movements, and all three emigration movements by juveniles were significantly nonrandom $(P<0.05)$ (Table 1$)$. However, many oak toads immigrated to and departed from ponds in all directions. Further, the mean angle of adult emigrations often did not correspond with the general vicinity of mean immigrations at the same ponds and during the same years. For example, in 1994 at Ponds 1 and 4, and in 1999 and 2002 at Pond 3, adults entered and exited in a nearly straight-line direction (rather exiting toward the vicinity of entry). On other occasions-for example, at Pond 2 in 1994 and 2000, and at Pond 6 in 1998-most oak toads emigrated in the same vicinity where most immigration had occurred. However, because oak toads were not marked individually we could not track movements of individuals. Directions of movements were infrequently tested at the same pond(s) during multiple years. At Pond 2, the mean angle of both immigration and emigration movements was similar during 1994 and 2000 (entering from and exiting toward the northern portion of the pond). At Pond 3 individuals entered from the west-southwest (moving east-northeast) during 1999, 2002, and 2003, but immigrations were not significantly directional during other years (1995, 1996, 1998). Emigrations were generally eastsoutheasterly at Pond 3 during 1996, 1998, 1999, and 2002. Adults entered and exited 

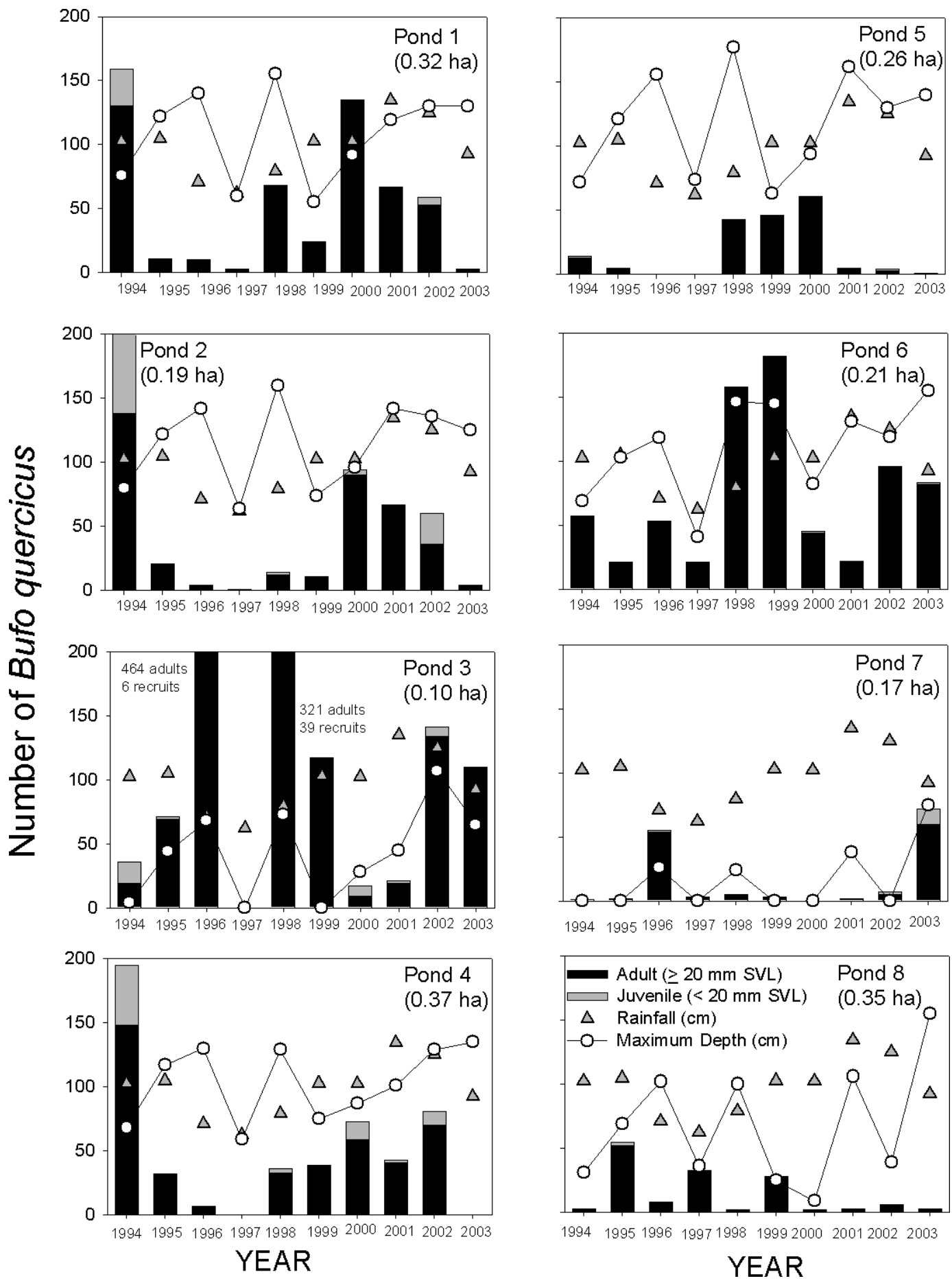

FIG. 2.-Total first captures of oak toad adults (May-August) and recruits (exiting juveniles) (June-October), and cumulative rainfall and maximum pond depth during May-August, 1994-2003, at eight ponds in the Ocala National Forest, Marion and Putnam counties, Florida, U.S.A. 


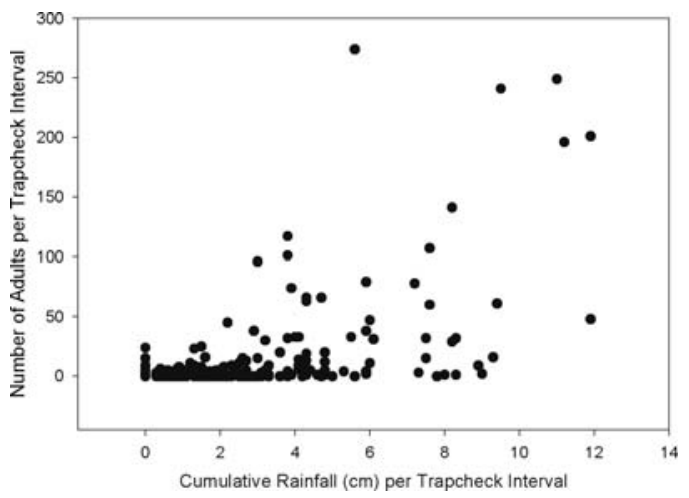

FIG. 3.-Relationship between cumulative rainfall and the number of adult oak toads captured per 2-3-day trapcheck interval during June-August, 1994-2004 at eight isolated, ephemeral ponds within longleaf pine-wiregrass sandhills, Ocala National Forest, Marion and Putnam Counties, Florida, U.S.A

Ponds 1-3 both from the direction of hardwood-invaded habitat (to the north, east, and west) and from the direction of savanna-like habitat (to the south and within 10-30 m).

Because of low recruitment, emigration by juveniles could be tested only three times. Substantial $(n \geq 30)$ immigration never occurred during the 10-year study period. All three tested emigrations by juveniles were significantly directional $(P<0.001)$. The mean direction of emigration at Pond 2 (1994) and Pond 3 (1998) was northerly, toward the hardwood-invaded habitat, but movement was southeasterly (also into hardwood-invaded habitat) at Pond 4 (1994) (Table 1).

\section{Spatio-Temporal Population Dynamics and Trends}

We found no relationship $\left(F_{1,8}=0.01 ; P=\right.$ 0.9387 ) between study year and the total number of first-captured adult oak toads, indicating that the population did not increase or decrease significantly during the 10-year study period (Fig. 4). Similarly, populations did not increase or decrease significantly at individual ponds $(P \geq 0.1251)$ during the 10 years.

A total of $21.1 \%$ of individuals were recaptured. Annual recapture rates ranged from $9.2-35.6 \%$ of first captures (Table 2). Most (13.3\% of first-captures) were recaptured during the same year, and $7.7 \%$ during a subsequent year. The rate of prior-year recaptures varied among years (1.5-18.2\% of
TABLE 1.-Orientation of adult (A) and juvenile (J) oak toads entering (En) or exiting (Ex) eight isolated, ephemeral ponds in the Ocala National Forest, Putnam and Marion counties, Florida (Feb. 1994-Jan. 2004). Only ponds and years having $n \geq 30$ individuals per age/direction class are included. Significantly directional movement (determined by Rayleigh's test) is denoted by asterisks $(* * *=P<0.001 ; * *=P<0.005 ; *=P<0.05)$.

\begin{tabular}{|c|c|c|c|c|c|c|c|}
\hline Year & $\begin{array}{c}\text { Pond } \\
\text { no. }\end{array}$ & Age & $\begin{array}{c}\text { Dirxn } \\
\text { direction }\end{array}$ & $n$ & $\begin{array}{c}\text { Mean } \\
\text { azimuth }\left(^{\circ}\right)\end{array}$ & $R$ & $Z_{\text {calc }}$ \\
\hline 994 & 1 & A & En & 67 & 161 & 19.3 & $5.56 * *$ \\
\hline 94 & 1 & A & & 6 & 155 & 18.52 & \\
\hline 994 & 2 & A & En & 88 & 159 & 28.3 & $9.12 * * *$ \\
\hline 994 & 2 & A & Ex & 50 & 6 & 29.04 & $16.86^{* * *}$ \\
\hline 994 & 2 & $\mathrm{~J}$ & Ex & 47 & 19 & 31.40 & $20.98 * * *$ \\
\hline 994 & 4 & A & En & 99 & 92 & 21.07 & $4.48^{*}$ \\
\hline 994 & 4 & A & Ex & 49 & 151 & 17.95 & \\
\hline 994 & 4 & $\mathrm{~J}$ & Ex & 40 & 130 & 20.11 & $10.11^{* * * *}$ \\
\hline 994 & 6 & $\mathrm{~A}$ & En & 98 & 44 & 26.80 & $16.32 * * *$ \\
\hline 995 & 3 & A & En & 40 & 78 & 10.35 & $2.68(\mathrm{NS})$ \\
\hline 995 & 8 & A & $\mathrm{E}$ & 35 & & 21.10 & $12.73 * * *$ \\
\hline 996 & 3 & A & En & 270 & 132 & 2.29 & 0.02 (NS \\
\hline 996 & 3 & A & Ex & 194 & 85 & 46.16 & 10.9 \\
\hline 996 & 7 & A & & 35 & 115 & 17.31 & \\
\hline 998 & 1 & A & & 32 & 148 & & \\
\hline 998 & 1 & A & & 36 & & 6.33 & \\
\hline 998 & 3 & A & En & 171 & 98 & 19.06 & $2.12(\mathrm{NS})$ \\
\hline 998 & 3 & A & Ex & 150 & 100 & 57.91 & $22.35 * * *$ \\
\hline 1998 & 3 & $\mathrm{~J}$ & Ex & 32 & 6 & 26.46 & $21.87 * * *$ \\
\hline 998 & 6 & $\mathrm{~A}$ & En & 92 & 13 & 36.58 & $14.54 * * *$ \\
\hline 998 & 6 & A & Ex & 66 & 153 & 25.11 & $9.55 * * *$ \\
\hline 999 & 3 & A & En & 81 & 84 & 19.94 & \\
\hline 999 & 3 & A & Ex & 36 & 72 & 17.69 & $8.70 * * *$ \\
\hline 999 & 6 & A & $\mathrm{E}$ & 134 & & 4.81 & 0. \\
\hline 999 & 6 & A & & & & 8.20 & \\
\hline 000 & 1 & A & & $\theta$ & 151 & 12.08 & 2.4 \\
\hline 000 & 1 & A & & 7 & 40 & 33.22 & $14.92 * * *$ \\
\hline 000 & 2 & A & En & 5 & 162 & 25.47 & $11.79 * * *$ \\
\hline 000 & 2 & A & Ex & 35 & 20 & 12.85 & $4.72 *$ \\
\hline 000 & 4 & A & En & 31 & 110 & 9.44 & 2.88 (NS \\
\hline 000 & 5 & A & En & 35 & 64 & 11.13 & $3.54 *$ \\
\hline 001 & 1 & A & En & 35 & 130 & 14.13 & $5.71 * *$ \\
\hline 2001 & 1 & A & Ex & 31 & 73 & 9.14 & $2.70(\mathrm{NS}$ \\
\hline 001 & 2 & A & En & 47 & 131 & 12.12 & $3.16^{*}$ \\
\hline 002 & 3 & A & $\mathrm{E}$ & 7 & 73 & 23.27 & 7.0 \\
\hline 2002 & 3 & A & Ex & 57 & 147 & 19.58 & $6.73 * * *$ \\
\hline 2002 & 4 & A & En & 36 & 174 & 0.92 & $0.02(\mathrm{NS})$ \\
\hline 2002 & 4 & A & Ex & 34 & 31 & 6.16 & $1.12(\mathrm{NS})$ \\
\hline 2002 & 6 & A & En & 75 & 84 & 16.62 & $3.68 *$ \\
\hline 2003 & 3 & A & En & 57 & 57 & 13.67 & $3.28 *$ \\
\hline 2003 & 3 & A & Ex & 52 & 83 & 9.29 & $1.66(\mathrm{NS})$ \\
\hline 2003 & 6 & A & En & 61 & 42 & 22.75 & $8.48^{* * *}$ \\
\hline 2003 & 7 & A & En & 38 & 108 & 12.54 & $4.14^{*}$ \\
\hline
\end{tabular}

individuals were recaptured that were first captured in a prior year). During 1997, a very dry year, we captured few oak toads. In the following year, recapture rates of toads that were first captured in 1996 was high $(16.0 \%$ of individuals that were first caught in 1996 were recaptured in 1998). High multi-year 


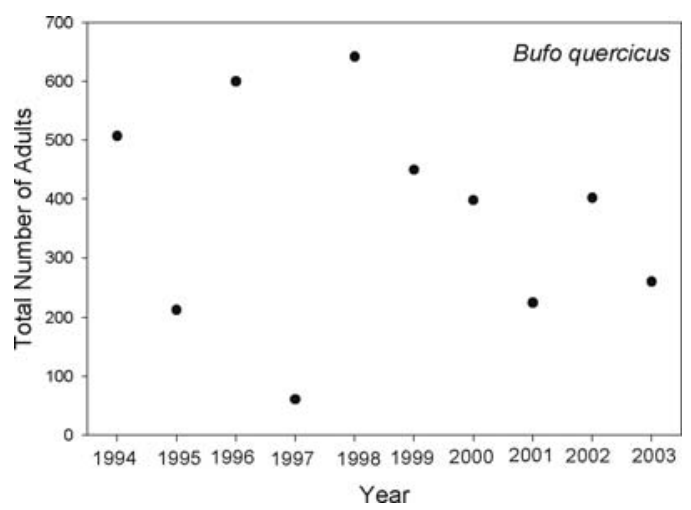

FIG. 4.-Relationship between time (study year) and number of adult ( $\geq 20 \mathrm{~mm}$ SVL) oak toads first-captured at eight isolated, ephemeral ponds, Ocala National Forest, Marion and Putnam Counties, Florida, U.S.A. Numbers of adults presented here are untransformed, but were logtransformed for correlation.

recapture rates also occurred in 1999, when $14.5 \%$ of individuals that were first captured in 1998 were recaptured. During 1998 we recaptured $10(4.7 \%)$ individuals that were first captured in 1995. These recaptured oak toads were at least 3- and possibly 4 years old, since we marked only large juveniles ( $>$ about $15 \mathrm{~mm}$ SVL) and (primarily) adults that probably were 1 year old in 1995 .

A total of $19.1 \%$ of oak toads was recaptured at the same pond as their original capture (Table 3 ). Only $1.9 \%$ of captured oak toads moved among ponds; most exchange was between Ponds 1-3, all within $132 \mathrm{~m}$ of one another. One individual that was originally captured at Pond 5 was recaptured at Pond 6, about $469 \mathrm{~m}$ away. Because most juveniles were not marked we were unable to determine whether they returned to natal ponds for breeding as adults or colonized new ponds.

At least one oak toad was captured each year at each pond with few exceptions (Pond 5 in 1996; Ponds 3, 4, and 5 in 1997; Pond 7 in 2000; Pond 4 in 2003) (Fig. 2). Presence did not necessarily indicate overall pond use. For example, although oak toads were present at Pond 7 during all years except one, they visited in substantial numbers only during 1996 and 2003. Similarly, absence from a pond probably did not indicate local extinction. For example, oak toads were absent from Pond 3 during 1997 (a dry year when few oak toads were captured at any pond), but bred there in high numbers there during 1998. Nearly all breeding adults were first-captures or recaptured at the same pond where they had been captured during a prior year, which indicates that they did not "rescue" Pond 3 from other ponds, but rather skipped the 1997 breeding season and remained in the surrounding uplands.

\section{Discussion}

Our 10-yr study illustrates the variability of oak toad breeding and recruitment among ponds and years. A study that included only one or a subset of our study ponds or years might have produced different results. For example, several ponds were little-used for several consecutive years (e.g., Ponds 1 and 2, 1995-1999; Pond 7, except in 1996 and 2003;

TABLE 2.- Total number of same-year (SY) and multi-year (MY) adult oak toads recaptured for 10 yr (Feb. 1994-Jan. 2004) at eight isolated ephemeral ponds, Ocala National Forest, Marion and Putnam counties, Florida, U.S.A.

\begin{tabular}{|c|c|c|c|c|c|c|c|c|c|c|c|c|c|}
\hline \multirow{2}{*}{$\begin{array}{l}\text { Recapture } \\
\text { (Recap) year }\end{array}$} & \multicolumn{10}{|c|}{ Year of first capture } & \multirow{2}{*}{$\begin{array}{l}\text { Tot. 1st } \\
\text { cap }\end{array}$} & \multirow{2}{*}{$\begin{array}{l}\text { Tot. } \\
\text { recap }\end{array}$} & \multirow{2}{*}{$\begin{array}{l}\text { Percent } \\
\text { recap }\end{array}$} \\
\hline & 1 & 2 & 3 & 4 & 5 & 6 & 7 & 8 & 9 & 10 & & & \\
\hline 1 & 85 & 0 & 0 & 0 & 0 & 0 & 0 & 0 & 0 & 0 & 507 & 85 & 16.8 \\
\hline 2 & 7 & 47 & 0 & 0 & 0 & 0 & 0 & 0 & 0 & 0 & 213 & 54 & 25.4 \\
\hline 3 & 1 & 14 & 57 & 0 & 0 & 0 & 0 & 0 & 0 & 0 & 600 & 72 & 12.0 \\
\hline 4 & 0 & 1 & 1 & 8 & 0 & 0 & 0 & 0 & 0 & 0 & 61 & 10 & 16.4 \\
\hline 5 & 0 & 10 & 96 & 7 & 99 & 0 & 0 & 0 & 0 & 0 & 642 & 212 & 33.0 \\
\hline 6 & 0 & 0 & 0 & 3 & 93 & 64 & 0 & 0 & 0 & 0 & 450 & 160 & 35.6 \\
\hline 7 & 0 & 0 & 0 & 0 & 24 & 22 & 50 & 0 & 0 & 0 & 398 & 96 & 24.1 \\
\hline 8 & 0 & 0 & 0 & 0 & 0 & 0 & 6 & 24 & 0 & 0 & 225 & 30 & 13.3 \\
\hline 9 & 0 & 0 & 0 & 0 & 0 & 0 & 0 & 2 & 35 & 0 & 402 & 37 & 9.2 \\
\hline 10 & 0 & 0 & 0 & 0 & 0 & 0 & 0 & 0 & 4 & 32 & 261 & 36 & 13.8 \\
\hline Tot. Rep & 93 & 72 & 154 & 18 & 216 & 86 & 56 & 26 & 39 & 32 & 3759 & 792 & 21.1 \\
\hline Tot. \% SY Recap & 16.8 & 22.1 & 9.5 & 13.1 & 15.4 & 14.2 & 12.6 & 10.7 & 8.7 & 12.3 & & & 13.3 \\
\hline Tot. \% MY Recap & 1.6 & 11.7 & 16.2 & 16.4 & 18.2 & 4.9 & 1.5 & 0.9 & 1.0 & n/a & & & 7.7 \\
\hline
\end{tabular}


TABLE 3.- Total number and percentage of adult oak toads recaptured at the same (SP) or another pond (IP) as first capture during $10 \mathrm{yr}$ (Feb. 1994-Jan. 2004) at eight isolated ephemeral ponds, Ocala National Forest, Marion and Putnam counties, Florida, U.S.A.

\begin{tabular}{|c|c|c|c|c|c|c|c|c|c|c|c|}
\hline \multirow{2}{*}{$\begin{array}{c}\text { Recapture } \\
\text { (Recap) pond }\end{array}$} & \multicolumn{8}{|c|}{ Pond of origin } & \multirow{2}{*}{$\begin{array}{l}\text { Total lst } \\
\text { cap }\end{array}$} & \multirow{2}{*}{$\begin{array}{l}\text { Total } \\
\text { recap }\end{array}$} & \multirow{2}{*}{$\begin{array}{c}\text { Recap } \\
(\%)\end{array}$} \\
\hline & 1 & 2 & 3 & 4 & 5 & 6 & 7 & 8 & & & \\
\hline 1 & 68 & 4 & 4 & 0 & 0 & 0 & 0 & 0 & 502 & 76 & 15.1 \\
\hline 2 & 15 & 61 & 15 & 0 & 0 & 0 & 0 & 0 & 384 & 91 & 23.7 \\
\hline 3 & 4 & 30 & 306 & 0 & 0 & 0 & 0 & 0 & 1261 & 340 & 27.0 \\
\hline 4 & 0 & 0 & 0 & 77 & 0 & 0 & 0 & 0 & 429 & 77 & 17.9 \\
\hline 5 & 0 & 0 & 0 & 0 & 21 & 1 & 0 & 0 & 176 & 22 & 12.5 \\
\hline 6 & 0 & 0 & 0 & 0 & 0 & 145 & 0 & 0 & 735 & 145 & 19.7 \\
\hline 7 & 0 & 0 & 0 & 0 & 0 & 0 & 25 & 0 & 134 & 25 & 18.7 \\
\hline 8 & 0 & 0 & 0 & 0 & 0 & 0 & 0 & 16 & 138 & 16 & 11.6 \\
\hline Tot & 87 & 95 & 325 & 77 & 21 & 146 & 25 & 16 & 3759 & 792 & 21.1 \\
\hline Tot. \% SP Recap & 13.5 & 15.9 & 24.3 & 17.9 & 11.9 & 19.7 & 18.7 & 11.6 & & & 19.1 \\
\hline Tot. \% IP Recap & 3.8 & 8.9 & 1.5 & 0.0 & 0.0 & 0.1 & 0.0 & 0.0 & & & 1.9 \\
\hline
\end{tabular}

Pond 5, 1994-1997 and 2001-2003). Others (e.g., Pond 6) were used by adults on a regular basis but apparently never produced substantial numbers of juvenile recruits. Data from only these ponds or years might have been interpreted as showing that oak toad populations were declining, whereas our longterm landscape-level data suggest otherwise (see Blaustein, 1994).

The relative landscape-level stability of the oak toad population was incongruous with the low capture rates of juveniles during most years and at most ponds, especially because only minimal short-distance inter-pond movement occurred. Highly directional movement patterns by juveniles, oriented exclusively within the $7.6 \mathrm{~m}$ spacing between fences, could have resulted in our not detecting recruitment events, but seems unlikely. Further, we did not observe oak toads climbing over fences (e.g., Dodd, 1991) or climbing from pitfall traps. However, on one occasion juveniles were observed avoiding traps by moving around the rims of pitfall traps (Ray Ashton, personal observations at Pond 3, 2003). Yet, capture rates of metamorphs of the closely-related southern toad, which are similar in size, were much higher (ca. 1000 captures) during some years, suggesting that capture rates also should reflect the relative recruitment rates of oak toad metamorphs. Confusion between oak toad and southern toad metamorphs was likely minimal, as metamorphs of these species have distinguishing characteristics. Also, most southern toad recruitment occurred during April and May (with less in June and July) whereas most oak toad recruitment occurred during June-October. If bias by trap-avoidance occurred, we assume that it was consistent among years and ponds, and therefore comparisons of recruitment among years and ponds should be valid if used as an index.

In our study, some ponds (e.g., Ponds 5 and 6) apparently produced virtually no juveniles, yet maintained moderate to high capture rates of adults during many years. Dodd (1994) sampled an ephemeral sandhill pond for 5 years using pitfall traps with a drift fence that completely encircled it. He also reported relatively high adult capture rates through the third of five breeding seasons sampled, even though the pond held water for more than a few weeks only during the first (1985) and third (1987) breeding seasons, and no juveniles were produced. Despite this, Dodd (1994) captured juveniles $(<23 \mathrm{~mm}$ SVL) entering and exiting the pond during fall 1988-summer 1989. Semlitsch et al. (1996) reported only one or two years of substantial recruitment at Rainbow Bay in South Carolina for most anurans during a $16-y r$ period. They suggested that population persistence at the Bay was aided by "rescues" from other ponds. However, we observed a pattern of consistently low recruitment at all eight of our study ponds, rendering this explanation less likely.

Sinsch (1992) found that metamorphic natterjack toads (B. calamita) emigrated from natal lakes or ponds but showed high breeding site fidelity in subsequent years. Because most juveniles were not marked we could not assess 
whether they returned to natal ponds for breeding as adults, or colonized new ponds. However, we captured very few juveniles entering study ponds, indicating that they were not immigrating to nonnatal ponds, at least as juveniles. Studies show adults of many amphibian species are philopatric (Blaustein et al., 1994), whereas others readily colonize newly-created ponds (Petranka et al., 2003).

Our data suggest that most $(>93 \%)$ oak toads breed during only one season. During his 5-year study, Dodd (1994) also reported that most recaptures occurred during the same season as their first-capture. Hamilton (1955) surmised that male oak toads first breed during the breeding season following transformation, and females during the second. This could explain why we captured (on average) more than twice as many males as females each year. Dodd (1994) also found that males outnumbered females by $1.75: 1$ at a north-central Florida pond.

Our multi-year recapture data suggest that mortality was high during most years, but apparently was reduced during years when breeding was suspended (e.g., 1997). Hamilton (1955) estimated that oak toads live 2-3 years. Assuming that oak toads first breed at age 1, our data also indicate that most live for about 2 years. However, some (about 6.4\%) lived longer. Some individuals apparently lived for at least 3, and possibly 4 years. We may have underestimated age at first breeding if breeding was suspended during some years. Similarly, our longevity estimates could be wrong if age at first breeding was $>1$ year, or if oak toad age cannot be estimated accurately by size due to determinate growth or slowing of growth with age. The possibility that oak toads avoided recapture by trap avoidance renders our conclusions about age somewhat speculative.

Oak toad activity was governed primarily by season. Most (98.5\%) adult captures occurred during May-September, and most juveniles were captured during June-October. Dodd (1994) reported similar annual activity patterns for oak toads. Our results showed that maximum temperature, cumulative rainfall, and rainfall patterns were correlated with year-round adult activity patterns. Clearly, seasonal cues such as temperature or photoperiod (which are autocorrelated) play a role in annual activity patterns of oak toads. Oak toad activity is commonly associated with heavy rainfall (Carr, 1940; Hamilton, 1955; Wright, 2002). Dodd (1994) reported that rainfall influenced movement, especially if a heavy rain was preceded by a dry period during summer; if rain fell regularly, its influence on movement was not pronounced. In our study, variability in adult capture rates was better explained (higher $r^{2}$ ) by weather variables when only peak breeding season data (June-August, when 92.6\% of adults were captured) were used. During peak breeding season, rainfall and barometric pressure had the greatest influence (among tested variables) on adult oak toad activity. In contrast, juvenile capture rates were best predicted by maximum temperature, mean daily barometric pressure, and an interaction between cumulative precipitation and the number of prior trapcheck intervals having no rain. Our results indicate that adults and juveniles may respond differently to rainfall patterns. The number of JuneAugust adult captures increased with heavier rainfall but was not influenced by the length of the dry period preceding rain. In contrast, metamorphs may remain near their natal ponds until moisture conditions are favorable for emigration to the surrounding uplands.

Our data suggest that pond hydrologyespecially hydroperiod, water level fluctuations, and pond depth-influenced use by adult oak toads, but pond use varied considerably regardless of those hydrological characteristics. For example, adult capture rates were high at Pond 3 in 1999, although the pond was dry during the entire breeding season. Similarly, the numbers of oak toads using ponds and annual patterns of pond use varied considerably among Ponds 1, 2, 4, 5, and 6, although all had similar hydrological characteristics (depth and hydroperiod). Dodd (1994) suggested that fewer adult oak toads were captured at a north-central Florida pond after 1988 because they moved to other nearby wetlands to breed. Our capture rates at all ponds also were negligible when May-September precipitation was low $(62 \mathrm{~cm})$ in 1997, as were water levels (maximum depth 36$64 \mathrm{~cm}$ at wet ponds; 2 ponds were dry). However, we found that inter-pond movement by adults was infrequent and mostly shortdistance. Our data suggest that oak toads 
suspended breeding activity, rather than moving to another pond, during drought.

Several hydrological characteristics were correlated with oak toad recruitment. Increased recruitment was associated with longer hydroperiods, probably because longer hydroperiods gave tadpoles adequate time to complete transformation (Pechmann et al., 1989). Breeding occurred over a period of several months, thus an extended hydroperiod during and beyond the breeding period would allow more tadpoles to complete transformation, which takes about five weeks for oak toads (Wright, 2002). Similarly, minimum pond depth during the oak toad breeding seasonan indicator of pond dry-downs and tadpole desiccation-was negatively associated with oak toad recruitment. In contrast, pond drydowns immediately before the breeding period had a positive influence on recruitment. This may have resulted from reductions of invertebrate predators immediately prior to the appearance and development of tadpoles (e.g., Semlitsch et al., 1996).

Breeding effort (adult first-captures) was not a significant predictor of oak toad recruitment in our model. As further evidence that breeding effort does not necessarily correspond with recruitment levels, we found only four tadpoles at only one of the eight ponds (Pond 2, 26 September 2001) during 2000-2001 box sampling for tadpoles (sampled at 3-4 week intervals at all eight ponds, if they were wet), despite moderate adult capture rates at most ponds during both years (A. Storfer, C.H. Greenberg, and G.W. Tanner, unpublished data). Clearly, successful recruitment depends on a complex interplay between adult breeding effort, competition, predation, and edaphic factors such as weather and pond hydrology (Alford, 1989; Petranka and Kennedy, 1999; Wilbur, 1987).

We found that both numbers of breeding adults and recruitment levels were higher at ponds within the hardwood-invaded sandhills than in the savanna-like sandhills. However, this should be interpreted with caution. A repeated measures effect suggested that site fidelity by oak toads could affect which ponds are consistently used most heavily. Further, habitat patchiness within the hardwood-invaded upland matrices, and the proximity of the two treatments, could complicate inter- pretation of these results. However, given the relatively wide distribution of oak toads within pine flatwoods and xeric habitat (Carr, 1940; Wright, 2002), it is not surprising that oak toads are tolerant of habitat changes associated with fire suppression, at least in the short term.

In southeastern fire-maintained habitats, many amphibian species may tolerate hardwood invasion (Greenberg, 1993; Greenberg, 2002; Litt et al., 2001; Meshaka and Layne, 2002; Palis 1998). Greenberg and Simons (1999) suggested that topographic and climatic variability, as well as spatial patchiness and variability in fire frequency, season, and intensity, historically permitted oaks to reach tree size in varying densities over time and across the high-pine landscape. Amphibians that evolved in a spatially and temporally dynamic landscape are likely to tolerate transient conditions within the upland matrix.

Although many adult movements were significantly directional, others $(32.5 \%)$ were not. Many individuals immigrated and emigrated from all directions even during movements that were statistically nonrandom. Dodd (1994) reported that immigrating females, emigrating juveniles, and males moved, on average, in nonrandom directions, but that there was a great deal of variability in orientation within these groups. Because we did not give oak toads individual markings, we could not determine whether individuals returned to their point of origin. However, within-season immigrations and emigrations at any given pond often were in different directions, suggesting that oak toads did not always return to the vicinity of their origin, or that oak toads from the entire surrounding upland neighborhood used ponds during a given breeding season, or both.

Directional movements are not necessarily indicative of upland habitat use, and oak toad directional movements did not appear to be particularly associated with either the hardwood-invaded or savanna-like upland matrices surrounding or adjacent to ponds. For example, adults apparently entered Pond 1 from hardwood-invaded sandhills, but exited toward the adjacent sandy road and savannalike sandhills. In contrast, Dodd (1994) reported that oak toads tended to enter his study pond from and exit toward a sandhill community to the west-southwest, rather than the xeric 
hammocks to the north. Dodd (1996) captured oak toads up to $914 \mathrm{~m}$ from the nearest wetland.

We found little evidence of a metapopulation structure of oak toads within our study area. We had few instances of apparent "extinction." Absence from a pond during a given year was often followed by breeding in high numbers at that pond during the next year. Semlitsch et al. (1996) suggested that migration from nearby ponds explained the persistence of breeding southern toads and spadefoot toads (Scaphiopus holbrookii) at Rainbow Bay, despite infrequent juvenile recruitment. In our study only a few adults moved among ponds, and then largely only among relatively proximate $(<132 \mathrm{~m})$ ponds. However, we were unable to determine whether juvenile oak toads immigrate to nonnatal ponds as adults for breeding. Juvenile recruitment was apparently low among all ponds, so "rescue" from those ponds would have been minimal if it occurred. Instead, our recapture data suggest that oak toads sometimes skipped breeding seasons at some ponds or during some years (e.g., 1997) and remained in the uplands surrounding the "extinct" ponds.

The "ponds as patches" paradigm (Marsh and Trenham, 2001), or metapopulation theory, supports the conservation of multiple ponds within landscapes to permit local inter-pond extinctions and recolonizations by amphibians to occur. We found little evidence that oak toads function as a metapopulation, although we were unable to determine whether juveniles immigrate to nonnatal ponds for breeding as adults. We did, however, observe extreme variability in breeding effort and juvenile recruitment among ponds and years. Although weather and pond hydrology influenced pond use by oak toads, those variables failed to explain most of the variation in use among years and ponds. Clearly, factors other than those we tested influence how and when oak toads select ponds for breeding, and whether juvenile recruitment will be successful. Regardless of whether oak toads exhibit a metapopulation structure, their conservation is best ensured by maintaining multiple ponds within a landscape. This will enhance the probability of recruitment within the landscape neighborhood during at least some years and ponds, and retain the possibility of interpond movement.

Acknowledgments.-Funding was provided by the USDA Forest Service, including the Ocala National Forest, the Longleaf Pine Ecosystem Restoration Program, and the Southern Research Station's Bent Creek Experimental Forest; the Department of EnergySavannah River Operations office through the Forest Service Savannah River Site and the Forest Service Southern Research Station under Interagency Agreement DE-AI09-76SR00056; and the Florida Fish and Wildlife Conservation Commission, Bureau of Wildlife Diversity Conservation, contracts NG99-014 and C1195. We thank J. Beach for field and logistical assistance, and for her dedication to this study. C. McMahon, D. Loftis, and J. Blake provided critical support to the study. S. Wazny, D. Wooten, R. Ashton, M. Welker, J. Smith, J. Staiger, J. Barichivich, R. Owen, D. Johnson, S. Johnson, J. Wiebe, K. Garren, and others have provided excellent field assistance and onsite project management. We also thank the Ocala National Forest staff officers, including L. Lowery, R. Lowery, C. Sekerak, J. Clutts, J. Marr, M. Clere, and the Ocala fire crew for their assistance. S. Johnson and K. Kinkead gave valuable suggestions for improving an earlier version of this manuscript.

\section{Literature Cited}

Alford, R. A. 1989. Variation in predator phenology affects predator performance and prey community composition. Ecology 70:206-219.

Blaustein, A. R., D. B. H. Wake, And W. P. Sousa. 1994. Amphibian declines: judging stability, persistence, and susceptibility of populations to local and global extinctions. Conservation Biology 8:60-71.

Carr, A. F., JR. 1940. A contribution to the herpetology of Florida. University of Florida Publications (Biological Science) 3:1-118.

DoDD, C. K., JR. 1991. Drift fence-associated sampling bias of amphibians at a Florida sandhill temporary pond. Journal of Herpetology 25:296-301.

1992. Biological diversity of a temporary pond herpetofauna in north Florida sandhills. Biodiversity and Conservation 1:125-142.

2. 1994. The effects of drought on population structure, activity, and orientation of toads (Bufo quercicus and B. terrestris) at a temporary pond. Ethology Ecology and Evolution 6:331-349.

- 1996. Use of terrestrial habitats by amphibians in the sandhill uplands of north-central Florida. Alytes 14:42-52.

GreEnberg, C. H. 1993. Effects of High-Intensity Wildfire and Silvicultural Treatments on Biotic Communities of Sand Pine Scrub. Ph.D. Dissertation, University of Florida, Gainesville, Florida, U.S.A.

- 2001. Spatio-temporal dynamics of pond use and recruitment in Florida gopher frogs (Rana capito aesopus). Journal of Herpetology 35:74-85.

. 2002. Fire, habitat structure and herpetofauna in the southeast. Pp. 91-99. In W. M. Ford, K. R. Russell, and C. E. Moorman (Eds.), Proceedings of the Symposium "The Role of Fire for Nongame Wildlife Management and Community Restoration: Traditional 
Uses and New Directions." $7^{\text {th }}$ Annual Conference of the Wildlife Society, 15 September 2000, Nashville, Tennessee. USDA Forest Service Gen. Tech. Rep. NE-288.

Greenberg, C. H., and R. W. Simons. 1999. Age, composition, and stand structure of old-growth oak sites in the Florida high pine landscape: implications for ecosystem management and restoration. Natural Areas Journal 19:30-40.

Greenberg, C. H., and G. W. Tanner. 2004. Breeding pond selection and movement patterns by Spadefoot Toads (Scaphiopus holbrookii) in relation to weather and edaphic conditions. Journal of Herpetology 38:569-577.

Hamilton, W. J., JR. 1955. Notes on the ecology of the oak toad in Florida. Herpetologica 11:205-210.

Hanski, I., AND D. Simberloff. 1997. The metapopulation approach, its history, conceptual domain, and application to conservation. Pp. 5-26. In I. A. Hanski and M. E. Gilpin (Eds.), Metapopulation Biology. Academic Press, San Diego, California, U.S.A.

Litt, A. R., L. P. Provencher, G. W. Tanner, and R. Franz. 2001. Herpetofaunal responses to restoration treatments of longleaf pine sandhills in Florida. Restoration Ecology 9:462-474.

Marsh, D. M., and P. C. Trenham. 2001. Metapopulation dynamics and amphibian conservation. Conservation Biology 15:40-49.

Meshaka, W. E., Jr., and J. N. Layne. 2002. Herpetofauna of a long-unburned sandhill habitat in south-central Florida. Florida Scientist 65:35-50.

Moler, P. E., and R. Franz. 1987. Wildlife values of small, isolated wetlands in the southeastern coastal plain. Pp. 234-241. In R. R. Odum, K. A. Riddleberger, and J. C. Ozier (Eds.), Proceedings of the $3^{\text {rd }}$ S.E. Nongame and Endangered Wildlife Symposium. Georgia Department of Natural Resources, Atlanta, Georgia, U.S.A.

PALis, J. G. 1998. Breeding biology of the gopher frog, Rana capito, in western Florida. Journal of Herpetology 32:217-223.

Pechmann, J. H. K., D. E. Scott, Jr., J. W. Gibbons, and R. D. Semlitsch. 1989. Influence of wetland hydroperiod on diversity and abundance of metamorphosing juvenile amphibians. Wetlands Ecology and Management 1:3-11.

Petranka, J. W., and C. A. Kennedy. 1999. Pond tadpoles with generalized morphology: is it time to reconsider their functional roles in aquatic communities? Oecologia 120:621-631.

Petranka, J. W., C. A. Kennedy, and S. S. Murray. 2003. Response of amphibians to restoration of a southern Appalachian wetland; a long-term analysis of community dynamics. Wetlands 23:1030-1042.

Semlitsch, R. D., D. E. Scott, J. H. K. Pechmann, and J. W. Gibbons. 1996. Structure and dynamics of an amphibian community: evidence from a 16-year study of a natural pond. Pp. 217-248. In M. L. Cody and J. A. Smallwood (Eds.), Long-term Studies of Vertebrate Communities. Academic Press, San Diego, California, U.S.A.

Skelly, D. K., E. E. Werner, and S. A. Cortwright. 1999. Long-term distributional dynamics of a Michigan amphibian assemblage. Ecology 80:23262337.

Skelly, D. K., K. L. Yurewicz, E. E. Werner, and R. A. RELYEA. 2003. Estimating decline and distributional change in ambhibians. Conservation Biology 17: 744-751.

SinSCH, U. 1992. Structure and dynamics of a natterjack toad metapopulation (Bufo calamita). Oecologia 90: 489-499.

Wilbur, H. M. 1987. Regulation of structure in complex systems: experimental temporary pond communities. Ecology 68:1437-1452.

Wright, A. H. 2002. Life-histories of the Frogs of the Okefinokee Swamp, Georgia. North American Salientia (Anura) No. 2. Cornell University Press, Ithaca, New York, U.S.A

Zar, J. H. 1984. Biostatistical Analysis. Prentice Hall, Englewood Cliffs, New Jersey, U.S.A.

Accepted: 6 June 2005 Associate Editor: Dean Adams 